\title{
Assessing the Effectiveness of an Integrated Speed Management Plan on Highways
}

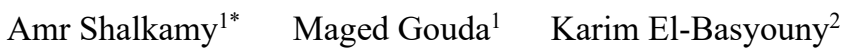 \\ 1.Graduate Research Assistant, Department of Civil and Environmental Engineering, University of Alberta, \\ Edmonton, AB, T6G 1H9 \\ 2.Associate Professor, Department of Civil and Environmental Engineering, University of Alberta, Edmonton, \\ $\mathrm{AB}, \mathrm{T} 6 \mathrm{G} 1 \mathrm{H} 9$ \\ *E-mail of the corresponding author: aamohame@ualberta.ca
}

\begin{abstract}
Manned speed enforcement has long been used as a safety measure to improve drivers' compliance with posted speed limits on highways. The sustainable presence of police squads at high-risk locations is key to the successful implementation of an enforcement program and is usually supported by other measures, such as educational campaigns, messages, and warnings. The goal of this study is to evaluate the effectiveness of an integrated speed management plan that is focused on manned traffic enforcement at three highway locations near the City of Leduc, Canada. Baseline speed data was collected and used to develop an enforcement deployment schedule. Following a public educational and engagement program, the enforcement plan was implemented. A detailed analysis was conducted for the speed data before, during, and after manned enforcement operations. To account for potential confounding factors, the evaluation method utilized a control site to correct for trends and other effects. The results showed that there was a statistically significant reduction in the average speed of vehicles that ranged from 1.14 to $8.96 \mathrm{~km} / \mathrm{h}$ while the number of speed violations dropped by up to $25.5 \%$ at enforcement locations. Overall, the results from this study demonstrated that implementing an integrated speed management program, with manned enforcement at its core, has a high potential to improve safety by improving compliance, reducing the number of violations, and decreasing the average speeds on highways. The sustained manned enforcement is expected to increase drivers' compliance with speed limits, which should eventually reduce collisions and improve safety.

Keywords: Vehicular Speed, Manned Enforcement, Speed Violations, Safety Impacts, Speed Limit Compliance DOI: $10.7176 / \mathrm{CER} / 13-1-04$
\end{abstract}

Publication date: January $31^{\text {st }} 2021$

\section{Introduction}

Road collisions exert a large social and economic burden on society, because they are a major cause of serious injuries and deaths, especially among economically productive young adults (Who 2015). According to the World Health Organization, road collision is among the top 10 leading causes of fatalities and is the principal reason for death in people aged 15-29. The societal impacts of this proclaimed epidemic have been estimated to cost hundreds of billions of dollars (Who 2015). In Canada, the number of injuries and fatalities resulting from motor vehicle collisions was 2,778 and 224,000, respectively in 2001. In 2004, the annual social cost associated with road collisions was estimated at $\$ 25$ billion annually (Tay 2010). This burden greatly impacts individual families and society at large, not only due to the loss of a loved one, but also as a result of sustaining life-threatening injuries that might leave some individuals with functional disabilities that may last from 6-12 months, or even longer, after being involved in a road collision (Peden 2008). As a result, there is a need to exert every effort to improve road safety and save the lives of victims that die on roads every day. This could be achieved through improving the design and safety of road facilities as well as launching integrated initiatives that aim to modifying drivers' behavior and prevent collisions (Shalkamy et al. 2018; Shalkamy \& El-Basyouny 2020)

Many factors contribute to road collisions such as limited sight distance, inclement weather, driver fatigue, and, most importantly, speeding - which was estimated to be the main contributing factor for $30 \%$ of fatal collisions (Shalkamy et al. 2020; Richards et al. 1985). It is generally accepted that speeding is a causal factor in collision occurrence with significant implications to the likely outcome of a road collision ( $\mathrm{Li}$ et al. 2015). Speed could be related to safety in two different ways. First, speeding increases the possibility of collision occurrence as higher speeds require longer stopping sight distance, lowering the chance of avoiding a collision. Second, the severity of a collision has a direct association with vehicle speed based on the relationship between mass and speed to energy (Islam et al., 2014). Nilsson used a power model to describe the effect of speed on safety and found a relationship between the mean speed and the number of collisions (Nilsson 2004). Indeed, Kloeden et al. (2002) found that a small increase in travel speed leads to a significantly higher risk of both the occurrence and severity of collisions.

Since the relationship between vehicle speed and the risk of collision occurrence and severity is wellestablished, it is very important to develop effective strategies to manage speeds and reduce violations. According to the Organisation for Economic Cooperation and Development (OECD), there are three predominant approaches 
to speed management measures, including engineering, education, and enforcement (OECD 2006). Engineering countermeasures range from reducing speed limits, adding signs, and improving sign visibility to improving the geometry of the road. Education measures include creating media campaigns to increase public awareness about the dangers of speeding. Speed enforcement aims to modify the behavior of drivers by first detecting and then ticketing violators who drive over the posted speed limits (Li et al. 2015). However, it may be argued that the most relied-upon approach to improving driver's compliance with speed limits is traffic-law enforcement initiatives (Bates et al. 2012).

Speed enforcement is a commonly used countermeasure to ensure drivers do not exceed the speed limit of a roadway. Apprehension and deterrence are two key functions of traffic enforcement. They are typically achieved through establishing traffic laws, policing these legislations, and applying penalties to offenders and violators (Watson et al. 1996). The use of coordinated manned traffic enforcement operations has been found to have significant improvements on road safety ( $\mathrm{Li}$ et al. 2015). Deterrence by way of manned enforcement is instantaneous, as police officers usually issue speeding tickets on the spot (Bates et al. 2012). Traffic officers also often share educational messages with violators with the goal of highlighting the dangers of speeding, which may have an additional positive and long-term effect on their driving behavior (Tay 2009). Police site visits have been regarded as an effective measure for deterring violators and improving safety (Bates et al. 2012). Marketing campaigns aimed at traffic safety were also found to be influential in reducing risky driving behaviors (Tay 2005). In fact, the impact the presence of police patrol vehicles have on reducing speed violations has been deeply investigated in the literature, but there are limited studies focused on studying the influence of incorporating enforcement operations with other speed management approaches (Elvik et al. 2009).

The integration of law enforcement with other key components, such as engineering and educational measures has recently come to the forefront of speed management plans (Islam \& El-Basyouny 2013). Since many road agencies are being encouraged to consolidate traffic enforcement with other measures (Retting 2017), evaluation of such an approach would assist agencies to decide whether to adopt this framework into their practices and safety plans. Thus, this study aims to develop and evaluate the effectiveness of an integrated speed management strategy, focused on using manned speed enforcement, on a portion of the Queen Elizabeth II (QEII) Highway near the City of Leduc in Alberta, Canada. This research uses a combination of strategies including engineering, enforcement, and education. The basic premise is that integrating speed enforcement with an educational awareness campaign alongside the installation of traffic signs can help improve safety by reducing the average speed, violations, and increasing vehicles' compliance with speed limits on the studied highway segment. The aim of this work was accomplished by analyzing speed data in a before-during-after evaluation method using a control group to account for potential confounding effects. To achieve this objective, the project was divided into three major phases. The first phase involved collecting baseline data to facilitate comparisons after the program is implemented. The second phase focused on developing a manned enforcement deployment schedule based on the collected speed data during the first phase and resource availability. The multi-phase deployment plan was periodically adjusted based on the data to maximize the benefits of enforcement operations. A public education and engagement program accompanied this deployment schedule. The third phase implemented the manned enforcement schedule while collecting additional data to monitor progress. The data collected during all phases was then used to evaluate the overall effectiveness of the program.

\section{Previous Studies}

Several studies in the literature have discussed the effectiveness of manned speed enforcement for improving speed compliance and reducing road collisions. Wilmots (2016) studied the effect of stationary police vehicles on the safety of two road segments. The study showed that there was a time halo effect of up to three weeks on one of the segments. Vaa (1997) investigated the influence of increased enforcement through police patrols and stationary enforcement on a $35-\mathrm{km}$ road segment in Norway. Results showed that the average speed of vehicles was reduced by 0.9 to $4.8 \mathrm{~km} / \mathrm{h}$. The percent of speed limit violations was also reduced for all hours except the morning rush hours. Tay (2009) evaluated the relative effectiveness of manned and automated speed enforcement for reducing road collisions in Queensland, Australia. They found that manned enforcement significantly reduced the number of both serious collisions and total collisions. Sisiopiku \& Patel (1999) evaluated the influence the presence of marked police cars had on vehicle speeds in two zones that experienced an increase in the posted speed limits. The results indicated that the average speed of vehicles reduced just upstream of the parked police vehicle, however, it increased again after passing the police patrol car.

Chen \& Tarko (2013) evaluated the effectiveness of police enforcement in work zones and concluded that an effective supplement to enforcement activity is the variable message sign. It was also found that enforcement activity has a distance halo effect of one mile downstream from the enforcement location. It is natural for drivers who slow down within enforcement sites to speed up after exiting the range of the enforcement corridor. However, Hauer et al. (1982) argued that this may not be always the case, especially when a high percentage of local drivers are repeatedly exposed to enforcement. It was also found that the time halo effect in such cases could last for one 
week after enforcement.

Goldenbeld \& van Schage (2005) investigated the influence mobile enforcement with increased intensity has on speed. The study showed that speed decreased significantly during the first year after the implementation of enforcement and was further reduced during the fourth year when the enforcement intensity was increased. Elvik (2011) used 11 studies to develop collision modification functions to describe the relationship between relative enforcement intensity and a reduction in injury collisions. It was assumed that injury collisions would decrease with an increase in enforcement intensity. The logarithmic and inverse functions were found to be ideal model forms to describe this relationship. It was indicated that the injury collisions would be reduced by $20 \%$ when doubling enforcement intensity.

Armour (1986) studied the effect of the presence of two police cars manned by officers using radar units on two two-lane road segments. The study concluded that the presence of police vehicles reduced speed limit violations by about two-thirds. It was also found that there was a time-halo effect of at least two days after the police vehicles had left. Furthermore, several studies found speed enforcement to be not only effective but also offer considerable safety improvements (Gouda \& El-Basyouny 2017; Li et al. 2015; Li et al. 2019; Elliott \& Broughton 2005; Wrapson et al. 2006; Walter \& Broughton 2011; Cruzado \& Donnel 2009). In a review that was conducted by Elliott \& Broughton (2005), it was shown that a reduction of $4.8 \mathrm{~km} / \mathrm{h}$ in the mean speed was achieved by using stationary and visible enforcement. When using stationary and hidden enforcement, the reduction in the mean speed ranged from 1 to $2.4 \mathrm{~km} / \mathrm{h}$. Some other studies (Wrapson et al. 2006; Walter \& Broughton 2011; Cruzado \& Donnel 2009) reported that using digital signs alongside the road has positive effects on reducing the travel speed. For instance, Walter \& Broughton (2011) reported a decrease of $2.25 \mathrm{~km} / \mathrm{h}$ in the average speed on a 30-mph road section when using speed indicator devices to alert drivers when their speed differed from the posted limit.

As discussed, dedicating police resources via squad presence to monitor speeds could reduce speeding offenses and road collisions on roads at appropriate times and selected locations. This shows the effectiveness of using speed enforcement to modify drivers' behaviors and improve safety. However, it is believed that sustainable reduction of speed limit violations requires a comprehensive and coordinated effort with a need to leverage all available resources into a unified framework to achieve the best-desired safety outcomes. This study focuses on developing, implementing, and evaluating an integrated approach to improve drivers' compliance to posted speed limits on highways. The study is designed such that it combines the use of different approaches to support the enforcement operation. First, a road safety assessment was conducted to identify existing concerns along the study corridor. Baseline data was then collected and used to propose a manned enforcement deployment schedule. This schedule was periodically updated to respond to changes in collected data, allowing the targeting of high-risk locations at times when most speed limit violations occur. In addition, road-safety educational initiatives were combined with the enforcement operation to increase drivers' awareness about the significance of the safety issue and to improve compliance. Public involvement was also a key component of the speed management program. A news release coinciding with the project implementation was distributed to increase awareness regarding the enforcement operation. The proposed framework is expected to lower driving speeds, improve compliance to posted speed limits, and improve safety.

\section{Speed Data}

Speed data was collected using a Stalker Traffic Data Collector device, which is a radar-based speed detection device that emits radar waves that strike a vehicle's surface and are reflected back. Data collected includes the speed and direction of travel for vehicles, vehicle count, and the date and time the data was collected. Data was collected at three different locations along a speed enforcement corridor of $4.5-\mathrm{km}$ in length. The first phase of speed data collection involved establishing the baseline data to facilitate comparisons after implementing the program. At that stage, speed data is a crucial input to provide an accurate overview of the existing pattern of speeding (i.e., before the implementation of any enforcement, engineering, or awareness activities) and the times and locations where most speed violations occur. To ensure that speed data represents the existing conditions, data was collected during this phase without any enforcement efforts and without any educational or engineering activities (i.e., before any media announcements or awareness campaigns, and prior to the installation of any signs). Baseline speed information was used in the preparation of an enforcement deployment schedule to target locations with higher speeds and to ensure that enforcement times coincide with the times when a high number of violations occur. The data collection process continued during the different phases including the baseline period, familiarization period, and both during and after the enforcement activity to facilitate an evaluation of how effective speed enforcement was after the program was implemented.

\section{Study Phases}

This study was compromised of three phases. In the first phase, a preliminary safety review was conducted and the baseline speed data was established. In phase two, a manned enforcement deployment plan was created, based 
on the results of the analyzed baseline data and availability of existing manned resources. This phase also included a public education and engagement program to increase the awareness about the enforcement activities. Finally, phase three focused on implementing the manned enforcement while collecting speed data to monitor progress both during and post enforcement presence. This was followed by an evaluation of the overall effectiveness of the program using data collected during all phases.

\subsection{Existing Speeding and Safety Concerns}

The Queen Elizabeth II (QEII) Highway, which is also known as Alberta Provincial Highway No. 2, is a major highway in Alberta, Canada. The highway has a posted speed limit of $110 \mathrm{~km} / \mathrm{h}$, passing through relatively flat terrain with three interchanges providing access to the City of Leduc. This portion of QEII passing through the City of Leduc has several horizontal curves. This highway segment has experienced safety concerns that need to be addressed in order to improve safety and accordingly reduce collisions. Examinations of traffic count data, collision records, and incident reports for the portion of the QEII passing within the City of Leduc revealed several concerns. Traffic counts collected in 2015, at the weighing scales just south of Leduc municipal boundaries, indicated that a large number of vehicles were observed exceeding the speed limit by $30 \mathrm{~km} / \mathrm{h}$ or greater in both directions of the highway. The counts also indicated that the average speed was very close to the posted speed limit. It was also concluded that a total of 16,578 vehicles were found travelling at more than $150 \mathrm{~km} / \mathrm{h}$. Furthermore, incident reports collected by Leduc Fire Service from 2010 to 2015 on QEII between the weigh scales and the Airport Road overpass showed that 78\% (171 out of 218) of all their recorded incidents were related to road collisions. Moreover, in 2014 a City of Leduc Peace Officer was struck by a vehicle while providing advanced collision warning for another incident further up the QEII. Figure 1 shows the location of the study area and the enforcement zone through the City of Leduc.

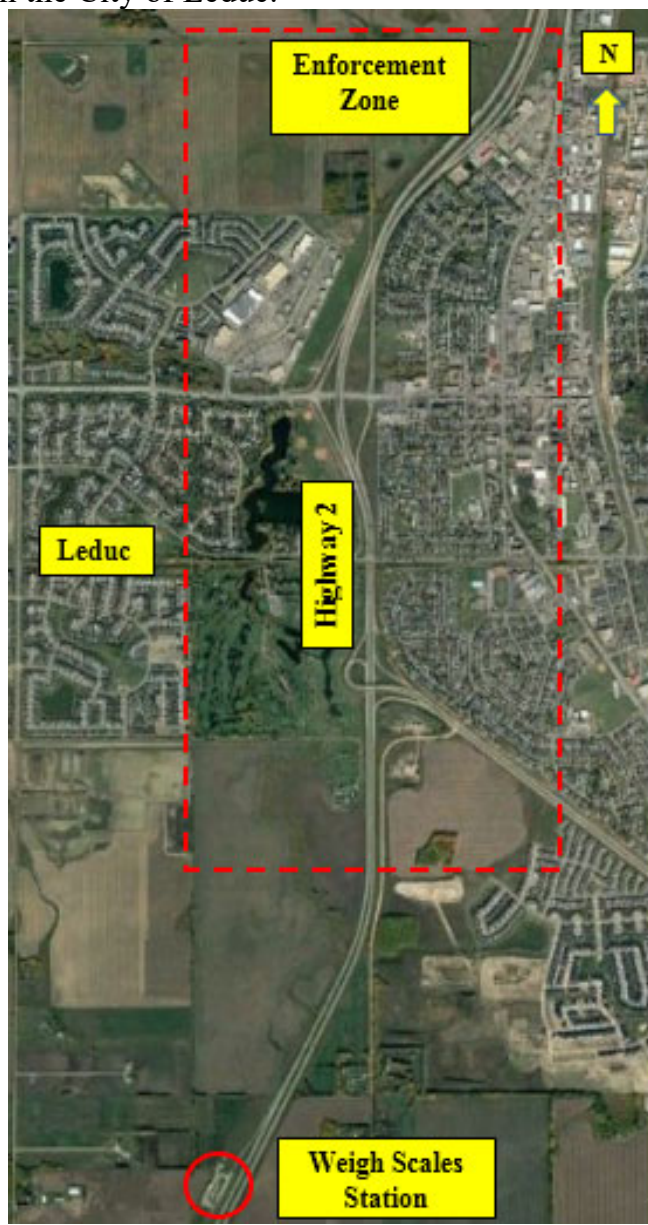

Figure 1. Enforcement zone on QEII Highway within the City of Leduc

\subsection{Educational Efforts and Engagement Program}

An effective speed management program typically requires that enforcement efforts be supplemented with a public education component and an engagement campaign. Such an approach often helps increase the general deterrence effects of the enforcement program. General deterrence is achieved through communicating the dangers of speeding to the general driving population. This is done by posting signs and running campaigns educating drivers 
about the consequences of speeding and the importance of safe driving. Drivers are also made aware of enforcement activity taking place along a highway corridor. Announcing locations of police enforcement has been found to be an effective approach in reducing average speeds and violations (Holland \& Conner 1996). More so, alerting the drivers about the corridors where enforcement activity is running is critical to avoid negative publicity. Thus, in this study, safety corridor signs and enforcement signs were posted at the entry of the enforcement zone to advise drivers about the use of enforcement equipment in order to reduce their violations and improve the level of traffic safety. In addition, as recommended by Alberta Traffic Enforcement Guidelines (2014), before the start of enforcement operations, it was advertised for a period of three months. Moreover, there was a four week familiarization period in which 'warning notices' were issued.

During both the familiarization and actual enforcement periods, the impact of speed enforcement is usually heightened when it is supported by public education campaigns (Bates et al. 2012). Typically, informing offenders of the dangers of speeding and providing pamphlets to drivers once they receive their speeding tickets is encouraged. This helps increase the effects of specific deterrence laws (i.e. decreases the likelihood a driver caught under the law will repeat the offense). The pamphlets and brochures are typically two or three pages in length and may contain information describing the danger of speeding, effect of speed on braking and sight distances, how to avoid receiving tickets, how the money from tickets is spent, collision costs that could be saved with safe driving or findings of a previous enforcement activity that successfully reduced the number of collisions or improved the level of safety. This would encourage motorists to consider changing their driving habits once they are exposed to the scientific evidence supporting speed reduction. As a part of this study, a customized pamphlet was created in the same format as regional cities' pamphlets for consistency. This brochure was given to drivers who were caught speeding. Attention to the importance of safe driving can also be drawn from other media, such as television programs and newspaper articles. This can be a good approach, especially because the media can greatly influence the attitudes of their audience. Thus, the City of Leduc put out a news release when the enforcement signs were installed in order to increase public awareness about upcoming enforcement activities.

\subsection{Speed Enforcement Implementation and Evaluation}

A typical mobile photo enforcement initiative involves deploying at least a two-man squad (one operator and one officer) in police marked vehicles, usually parked on the side of a road, to catch speed violations. A deployment plan for an enforcement program determines the presence of police squads at specific locations and times. It gives detailed information about the enforcement schedule, such as the number of visits per day, number of hours per visit, and times of enforcement. Thus, this plan is the key to a successful and effective enforcement program (Li et al. 2017). It is widely accepted that long durations of deployment and more frequent visits usually reduce speed violations and collisions. Limited available resources in most jurisdictions mean it is not always possible to implement such enforcement practices. Drivers tend to recall the presence of an enforcement vehicle up to several weeks after the event, this is known as the time halo effect. Drivers also slow down several kilometers upstream and downstream of the relevant road segment, known as the distance halo effect (Kim et al. 2016; Rothengatter, T. \& Goldenbeld 1999). Chen et al. 2000 concluded that a halo effect could remain three- to four- days and up to two- to eight- weeks before drivers' behaviors return to that observed prior to enforcement activity. Based on the collected speed data, enforcement times are determined such as they have the highest speed violations. In this study, a randomized scheduling enforcement method was used to develop a deployment plan based on the best practices from the literature. After the implementation of the educational and enforcement measures, the effectiveness of the proposed techniques for changing driver speeding behaviour was monitored and evaluated.

\section{Methodology}

To assess the effectiveness of the program, several performance indicators, such as average speed and the number of posted speed limit violators, were considered in the evaluation process. The analysis of enforcement effectiveness was divided into two parts. A microscopic analysis was first conducted where performance indicators during enforcement hours were compared to the same hours without enforcement one day before and another day after its deployment. A macroscopic analysis was also carried out where performance indicators of the before and during periods were compared. In this part, speed data of enforcement hours was aggregated over enforcement days to represent the during period dataset. For the pre-enforcement operation period, speed data of the same hours during the months of February, March, and April (i.e, before enforcement operation) were used in the comparison. In the microscopic analysis, hypothesis testing using a two-sample t-test was performed to assess the hypothesis that speed limit violations, percentage of speed limit violations, and average speed during enforcement hours were significantly lowered compared to the same hours without enforcement on the day before and the day after. The analysis focused on weekdays (i.e., Tuesdays, Wednesdays, and Thursdays) as these days have a consistent travel behavior pattern compared to weekends (i.e., Sundays and Saturdays) or shoulder weekdays (i.e., Mondays and Fridays). The null hypothesis is that speed limit violations, the average percentage of speed limit violations, and average speed during enforcement site-visits are not significantly different from the average values during 
corresponding hours on days without enforcement. The alternative hypothesis is that the values during site-visits are significantly lower compared to the average during corresponding hours on days without enforcement. First, the pooled standard deviation of two samples is estimated, and then the t-statistic is calculated, as shown in equations 1 and 2. Finally, the df and t-statistic are used to determine the corresponding p-value, which represents the area under the curve of the t-distribution (Snedecor \& Cochran 1967). If the calculated p-value is lower than 0.05 , then the alternative hypothesis is accepted, and the difference is considered significant at the $95 \%$ confidence level.

$$
\begin{aligned}
s_{p} & =\sqrt{\frac{\left(n_{1}-1\right) s_{1}^{2}+\left(n_{2}-1\right) s_{2}^{2}}{n_{1}+n_{2}-2}} \\
t & =\frac{\bar{x}_{1}-\bar{x}_{2}}{s_{p} \sqrt{\frac{1}{n_{1}}+\frac{1}{n_{2}}}} \\
d f & =n_{1}+n_{2}-2
\end{aligned}
$$

where, $n_{1}$ and $n_{2}$ are the sample sizes; $\bar{x}_{1}$ and $\bar{x}_{2}$ are the samples weighted means; $s_{1}$ and $s_{2}$ are the samples weighted standard deviations; $s_{p}$ is the pooled standard deviation of the two samples; $t$ is the $t$-statistic; and $d f$ is the degree of freedom.

Enforcement site-visits at the test sites lasted from four to eight hours. The reduction in violations and speed and significance at the different sites were used to make inferences about the effectiveness of enforcement operations at the studied locations. The normality assumption of the t-test was validated for the tested samples using the Anderson-Darling test ( Snedecor \& Cochran 1967). To account for the effect of traffic volume, the t-test was performed using the weighted mean (equation 4) and weighted variance (equation 5) for the tested parameter. However, the traffic volume weighting was not necessary for testing the percentage of violations as it had already been taken into account.

$$
\begin{gathered}
\bar{x}_{\mathrm{W}}=\frac{\sum_{i=1}^{n} \mathrm{x}_{i} m_{i}}{\sum m_{i}} \\
s_{W}^{2}=\frac{\frac{\sum\left(m_{i} x_{i}^{2}\right)}{\bar{m}}-n \bar{x}_{W}^{2}}{n-1}
\end{gathered}
$$

where $\bar{x}_{\mathrm{w}}$ is the weighted mean, $s_{w}^{2}$ is the weighted variance, $X_{\mathrm{i}}$ is the average value of a parameter in one hour, $n$ is the number of testing hours, $m_{i}$ is the traffic volume recorded in one hour (=weights), $i$ indicates the $i^{t h}$ value of the a parameter in one hour, and $\bar{m}$ is the average volume per hour $\left(\Sigma m_{i} / \mathrm{n}\right)$. The values of speeds and violations were corrected using data from the control site during the same hours, to account for any confounding factors before attributing the reduction in violations and speeds at the enforced locations to enforcement operations. Values of the before or during periods used in the t-test were corrected using equations 6 and 7 (Elvik et al. 2009).

$$
\begin{aligned}
& \text { Adjustment factor }=\frac{\text { Parameter value in the after period at control sites }}{\text { Parameter value in the before period at control sites }} \\
& \bar{x}_{1}^{*}=\bar{x}_{1} * \text { Adjustment factor }
\end{aligned}
$$

where $\bar{x}_{1}$ is the parameter value at the test site, and $\bar{x}_{1}^{*}$ is the corrected parameter in the before or during period used in the $t$-test.

Finally, change in the variance of speeds was tested using the F-test. An F-test is used to investigate if the variance of two populations is equal or significantly different. The null hypothesis is that the variances of the two samples are not significantly different. The alternative hypothesis is that they are significantly different. The test statistic of the F-test is expressed as in equation (8).

$$
F=\frac{s_{1}^{2}}{s_{2}^{2}}
$$

where $s_{1}^{2}$ and $s_{2}^{2}$ are the sample variances. The more this ratio deviates from 1 , the stronger the evidence for unequal population variances. The hypothesis that the two variances are equal is rejected if $\left(F>F_{\alpha / 2, N_{1}-1, N_{2}-1}\right)$, 
where $F_{\alpha / 2, N_{1}-1, N_{2}-1}$ is the critical value of the $F$-distribution with $N_{1}-1$ and $N_{2}-1$ degrees of freedom and a significance level of $\alpha$ (US Department of Commerce 2006).

In the macroscopic analysis, the before and during periods were compared following the same procedure.

\section{Results and Discussion}

Table 1 shows a summary of the microscopic analysis results at the studied locations. The performance during the enforcement times was compared to the performance on the day just before and just after police site visits. Significant reductions in average speed and violations were found at different locations on different days.

\subsection{Location 1}

On May 24th the analysis results show that there was a statistically significant reduction of $5.56 \mathrm{~km} / \mathrm{h}$ in the average speed of vehicles during the enforcement period compared with the same hours on the day before enforcement activity. On the day after enforcement, there was a statistically significant increase in the average speed of vehicles by $5.89 \mathrm{~km} / \mathrm{h}$ compared to the same hours during the enforcement. Comparing the average speed of vehicles on the day after enforcement to the average speed during the same hours of enforcement on the day before shows that there was a negligible increase in the average speed, which was not statistically significant.

Speed limit violations significantly dropped by 335 violations during enforcement hours compared to the day before enforcement during the same hours. However, there was a statistically significant increase of 545 speed limit violations on the day after the enforcement during the same hours, indicating a limited time halo effect.

Reduction in the percentage of violations during enforcement hours was $12.58 \%$ compared to the day before. There also was a statistically significant increase of $16.07 \%$ in the percentage of violations in the after-enforcement period compared to the during-enforcement period over the same hours.

Finally, the speed variance during the enforcement site-visit was significantly high compared to the before and after periods over the same enforcement hours. The increase suggests that enforcement presence causes vehicles' speeds to be more dispersed around the mean speed value. In other words, enforcement presence has a different effect on the behavior of groups of drivers. It is expected that the variance value is reduced as drivers become familiarized with enforcement operations at the prescribed locations.

\subsection{Location 2}

Analysis results at this location show similar results. When the enforcement hours on the day before and the day of enforcement are compared, there was a statistically significant reduction in the average vehicle speeds ranging from 1.4 to $4.25 \mathrm{~km} / \mathrm{h}$ over the four days of enforcement at this location. On the day after enforcement, there was a statistically significant increase in the average speed of vehicles ranging from 1.03 to $4.33 \mathrm{~km} / \mathrm{h}$ compared to the same hours during the enforcement.

Over the four days, there was a statistically significant drop in speed limit violations ranging from 79 to 144 during enforcement site-visits compared to the day before enforcement. The results seem to suggest that there might be an extended time halo effect on the number of speed limit violations after enforcement operations have ended. However, when the number of violations on the day after enforcement is compared to the number on the day of enforcement, there was a statistically significant increase that ranged from 60 to 175, indicating that the time halo effect of the enforcement had already ended.

When the enforcement was in place, there was a drop in the percentage of violations ranging between 8 and $12.44 \%$ compared to the before period. On the next day to enforcement operations, the percentage of speed limit violations increased significantly with differences ranging from 9.13 to $17.25 \%$ compared to the enforcement times. In addition, over three out of the four days, the speed variance during enforcement hours experienced a significant rise compared to its values on the before and the after days suggesting that the presence of enforcement activity causes vehicle speeds to be scattered around the mean value. This pattern might indicate the various influence the enforcement operations have on different groups of drivers.

\subsection{Location 3}

Similar conclusions can be drawn from the results at this location. During the enforcement time, the average speed of vehicles decreased by $1.93 \mathrm{~km} / \mathrm{h}$ compared to the same time on the day just before the police site visit. When the comparison is made with the day after enforcement, it can be seen that the average speed experienced a statistically significant decrease of $4.11 \mathrm{~km} / \mathrm{h}$. Although the number of speed limit violations had a statistically significant drop of 103 violations during enforcement hours compared the same time period during the day before, it rose significantly by 85 violations during the same hours on the next day. Comparing the number of drivers who violated the posted speed limit on the day after to those on the day before the enforcement site visit, with a difference of 46 violations, shows that the number of violators on the day after was statistically significantly lower than the number of violators recorded on the day before. Using the percentage of speed limit violations in the comparison showed similar results. In addition, the speed variance during enforcement operations was 
significantly higher than the values during the same hours in the before and after days, leading to similar conclusions.

Table 1. Microscopic Changes in Speed Performance Indicators Pre, During, and Post Enforcement Operation

\begin{tabular}{|c|c|c|c|c|c|c|c|c|c|c|c|c|}
\hline Location & Date & Hours & Performance Indicator & Before Values (B) & During Values (D) & After Values (A) & $\mathbf{B} / \mathbf{D}^{*}$ & $\mathrm{D} / \mathrm{A}^{*}$ & $\mathbf{B} / \mathbf{A}^{*}$ & $\begin{array}{l}\text { B/D Test } \\
\text { ( } p \text {-value })\end{array}$ & $\begin{array}{l}\text { D/A Test } \\
(p \text {-value })\end{array}$ & $\begin{array}{l}\text { B/A Test } \\
\text { ( } p \text {-value })\end{array}$ \\
\hline \multirow{4}{*}{1} & \multirow{4}{*}{ May, 24th } & \multirow{4}{*}{5} & Av. Speed $(\mathrm{km} / \mathrm{h})$ & 106.03 & 100.47 & 106.36 & -5.56 & 5.89 & 0.33 & 0.014 & 0.009 & 0.508 \\
\hline & & & Violation Numbers & 736 & 526 & 1002 & -335 & 545 & 254 & 0.003 & 0.000 & 0.001 \\
\hline & & & Violations (\%) & 36 & 24 & 40 & -12.58 & 16.07 & 3.63 & 0.012 & 0.007 & 0.042 \\
\hline & & & Variance ( $F$-tested) & 1.01 & 13.4 & 0.12 & 12.39 & -13.28 & -0.889 & 0.014 & 0.000 & 0.032 \\
\hline \multirow{4}{*}{2} & \multirow{4}{*}{ May, 16th } & \multirow{4}{*}{7} & Av. Speed $(\mathrm{km} / \mathrm{h})$ & 108.13 & 104.41 & 106.98 & -1.9 & -2.57 & 0.25 & 0.119 & 0.032 & 0.643 \\
\hline & & & Violation Numbers & 236 & 152 & 254 & -79 & 60 & -42 & 0.018 & 0.049 & 0.069 \\
\hline & & & Violations (\%) & 40.27 & 24.24 & 35.74 & -12.44 & $10.60 \%$ & -2.31 & 0.025 & 0.012 & 0.363 \\
\hline & & & Variance $(F$-tested $)$ & 2.06 & 7.53 & 0.35 & 5.55 & -7.18 & -1.64 & 0.064 & 0.000 & 0.026 \\
\hline \multirow{4}{*}{2} & \multirow{4}{*}{ Jul., 21st } & \multirow{4}{*}{5} & Av. Speed $(\mathrm{km} / \mathrm{h})$ & 104.23 & 101.72 & 105.67 & -2.51 & 3.95 & 1.44 & 0.093 & 0.020 & 0.094 \\
\hline & & & Violation Numbers & 238 & 94 & 269 & -144 & 175 & 31 & 0.000 & 0.000 & 0.089 \\
\hline & & & Violations (\%) & 22.08 & 11.83 & 29.08 & -10.25 & $17.25 \%$ & 7.00 & 0.001 & 0.000 & 0.010 \\
\hline & & & Variance $(F$-tested) & 1.19 & 6.35 & 1.73 & 5.16 & -4.62 & 0.54 & 0.067 & 0.117 & 0.362 \\
\hline \multirow{4}{*}{2} & \multirow{4}{*}{ Aug., 5th } & \multirow{4}{*}{5} & Av. Speed $(\mathrm{km} / \mathrm{h})$ & 105.92 & 101.67 & 106 & -4.25 & 4.33 & 0.08 & 0.078 & 0.068 & 0.909 \\
\hline & & & Violation Numbers & 233 & 146 & 278 & -87 & 132 & 45 & 0.044 & 0.011 & 0.029 \\
\hline & & & Violations (\%) & 27.87 & 16.89 & 28.95 & -10.98 & $12.06 \%$ & 1.08 & 0.049 & 0.036 & 0.372 \\
\hline & & & Variance $(F$-tested $)$ & 1.67 & 14.71 & 0.62 & 13.04 & -14.09 & -1.05 & 0.029 & 0.005 & 0.180 \\
\hline \multirow{4}{*}{2} & \multirow{4}{*}{ Nov., 24th } & \multirow{4}{*}{5} & Av. Speed $(\mathrm{km} / \mathrm{h})$ & 107.4 & 106 & 108 & -1.4 & 2 & 0.6 & 0.019 & 0.002 & 0.350 \\
\hline & & & Violation Numbers & 219 & 121 & 226 & -98 & 105 & 7 & 0.070 & 0.004 & 0.400 \\
\hline & & & Violations (\%) & 37.5 & 29.5 & 38.63 & -8.00 & $9.13 \%$ & 1.13 & 0.019 & 0.000 & 0.350 \\
\hline & & & Variance $(F$-tested $)$ & 1.75 & 0.432 & 0.136 & -1.32 & -0.30 & -1.61 & 0.100 & 0.320 & 0.080 \\
\hline \multirow{4}{*}{3} & \multirow{4}{*}{ May, 16th } & \multirow{4}{*}{7} & Av. Speed $(\mathrm{km} / \mathrm{h})$ & 96.25 & 92.7 & 96.81 & -1.93 & 4.11 & 1.8 & 0.260 & 0.013 & 0.156 \\
\hline & & & Violation Numbers & 221 & 115 & 232 & -103 & 85 & -46 & 0.033 & 0.076 & 0.063 \\
\hline & & & Violations (\%) & 18.42 & 10.44 & 19.58 & -6.34 & $8.76 \%$ & 2.18 & 0.066 & 0.021 & 0.031 \\
\hline & & & Variance $(F$-tested) & 7.02 & 12.93 & 2.48 & 6.14 & -10.45 & -4.36 & 0.226 & 0.033 & 0.121 \\
\hline
\end{tabular}

*Control location effect taken into account (-ve: reduction \& +ve: increase)

Table 2 shows a summary of the analysis results of the macroscopic analysis comparing the performance during the before and after periods. There was a statistically significant reduction in average speeds in the magnitude of 8.96 and $5.02 \mathrm{~km} / \mathrm{h}$ at locations 2 and 3, respectively. The reduction of $1.14 \mathrm{~km} / \mathrm{h}$ at location 1 was not statistically significant. A widely cited power model (Nilsson 2004) that relates the change in speed to safety was used to estimate the expected reduction in road collisions corresponding to lowering average speeds. It is worth noting that a reduction of $8.96 \mathrm{~km} / \mathrm{h}$ in the average speed at location 2 translates to about $24 \%$ and $13 \%$ reductions in fatal and injury collisions, respectively. At location 3, the expected reduction in collisions roughly estimated at $21 \%$ for fatal crashes and $11 \%$ for injury collisions.

There was a statistically significant drop in the percentage of speed limit violations ranging from 4.62 to $25.53 \%$. Moreover, the speed variance in the during period was high compared to the before period, however, this increase was not statistically insignificant at all locations.

The analysis of results for all locations shows similar trends indicating that the enforcement operations were effective in reducing the average speed and the speed limit violations. The presence of manned enforcement contributed to a reduction in violations for the duration of the project. However, the scarcity of deployment resources hinders the sustainability of the average speed and violation decrease. Hence, more sustained enforcement levels should have a more profound effect on improving compliance levels on Highway 2 near the City of Leduc. The availability of dedicated resources on a continuous basis will increase speed compliance and reduce speed limit violations, which in turn should bring about improved safety.

Table 2. Macroscopic Changes in Speed Performance Indicators Before and During Enforcement Operation

\begin{tabular}{|c|c|c|c|c|c|}
\hline \multirow{2}{*}{ Location } & Variable & $\begin{array}{c}\text { Before } \\
\text { Values (B) }\end{array}$ & $\begin{array}{c}\text { During } \\
\text { Values (D) }\end{array}$ & B/D* & $\begin{array}{c}\text { B/D Test } \\
(p \text {-value) }\end{array}$ \\
\hline \multirow{3}{*}{1} & $\begin{array}{c}\text { Average Speed } \\
(\mathrm{km} / \mathrm{h})\end{array}$ & 100 & 100.41 & -1.14 & 0.133 \\
\cline { 2 - 6 } & Violations (\%) & 25.37 & 20.75 & -4.62 & 0.063 \\
\cline { 2 - 6 } & Variance (F-tested) & 1.13 & 3.73 & 2.60 & 0.302 \\
\hline \multirow{2}{*}{3} & $\begin{array}{c}\text { Average Speed } \\
(\mathrm{km} / \mathrm{h})\end{array}$ & 106.88 & 99.78 & -8.96 & 0.000 \\
\cline { 2 - 6 } & Violations (\%) & 36.22 & 10.69 & -25.53 & 0.000 \\
\cline { 2 - 6 } & Variance (F-tested) & 0.63 & 2.05 & 1.42 & 0.308 \\
\hline & Average Speed & 97.34 & 91.82 & -5.02 & 0.011 \\
\cline { 2 - 6 } & Violations (\%) & 16.88 & 6.80 & -10.08 & 0.001 \\
\cline { 2 - 6 } & Variance (F-tested) & 2.81 & 8.52 & 5.713 & 0.330 \\
\hline
\end{tabular}

*Control location effect taken into account (-ve: reduction $\&+v e$ : increase) 


\section{Conclusions}

The objective of this study was to use police patrol cars supported by educational and engagement efforts to improve compliance with the posted speed limit with the ultimate goal of enhancing the safety of all commuters on highways. Based on the collected speed data, the enforcement schedule was set to target the times with the highest number of speed violations, and a deployment schedule was developed to determine the placement of police squads at specific locations and times. After implementing the educational and enforcement activities, the effectiveness of the program was monitored and evaluated. Using statistical tests, the before, during, and after enforcement periods were compared. The results show similar trends at all locations indicating that the study was effective in reducing the average speed and the number of speed violations.

Overall, the decrease in the average speed of vehicles was up to $8.96 \mathrm{~km} / \mathrm{h}$. This yielded an expected reduction of up to $24 \%$ and $13 \%$ in fatal and injury collisions, respectively. The reduction in the percent of speed violations was up to $12.58 \%$ and $25.53 \%$ during enforcement operations for microscopic and macroscopic analysis respectively. The results suggest that there was an extended time halo effect for average speed and number of violations after enforcement operations. Finally, results from this study demonstrated that the use of manned enforcement combined with engineering and educational measures contributed to a reduction in both speed violations and average travel speed. However, the scarcity of resources and deployment hinder the sustainability of the activities and subsequent reductions. Hence, more sustained enforcement levels should have a more profound effect on improving road safety. The availability of dedicated resources on a continuous basis will increase speed compliance and reduce speed limit violations, which in turn will lead to improved road safety.

\section{Acknowledgments}

The authors would like to thank the City of Leduc for their financial support and for providing the data used in this study.

\section{References}

Armour, M., 1986. The effect of police presence on urban driving speeds. ITE journal, 56(2), pp.40-45.

Automated traffic enforcement technology guidelines (2014). Alberta, Canada. https://open.alberta.ca/publications/automated-traffic-enforcement-technology-guidelines. Accessed March 2018.

Bates, L., Soole, D. and Watson, B., 2012. The effectiveness of traffic policing in reducing traffic crashes. Policing and security in practice, pp.90-109.

Chen, E., and A. P. Tarko. Police enforcement strategies and speed reduction in work zones. 2013. Presented at 92nd Annual Meeting of the Transportation Research Board, Washington, D.C.

Chen, G., Wilson, J., Meckle, W. and Cooper, P., 2000. Evaluation of photo radar program in British Columbia. Accident Analysis \& Prevention, 32(4), pp.517-526.

Cruzado, I. and Donnell, E.T., 2009. Evaluating effectiveness of dynamic speed display signs in transition zones of two-lane, rural highways in Pennsylvania. Transportation research record, 2122(1), pp.1-8.

Elliott, M.A. and Broughton, J., 2005. How methods and levels of policing affect road casualty rates. London: TRL Limited.

Elvik, R., 2011. Developing an accident modification function for speed enforcement. Safety Science, 49(6), pp.920-925.

Elvik, R., Vaa, T., Hoye, A. and Sorensen, M. eds., 2009. The handbook of road safety measures. Emerald Group Publishing.

Goldenbeld, C. and van Schagen, I., 2005. The effects of speed enforcement with mobile radar on speed and accidents: An evaluation study on rural roads in the Dutch province Friesland. Accident Analysis \& Prevention, 37(6), pp.1135-1144.

Gouda, M. and El-Basyouny, K., 2017. Investigating time halo effects of mobile photo enforcement on urban roads. Transportation research record, 2660(1), pp.39-47.

Hauer, E., Ahlin, F.J. and Bowser, J.S., 1982. Speed enforcement and speed choice. Accident Analysis \& Prevention, 14(4), pp.267-278.

Holland, C.A. and Conner, M.T., 1996. Exceeding the speed limit: an evaluation of the effectiveness of a police intervention. Accident Analysis \& Prevention, 28(5), pp.587-597.

Islam, M.T. and El-Basyouny, K., 2013. An integrated speed management plan to reduce vehicle speeds in residential areas: implementation and evaluation of the Silverberry Action Plan. Journal of safety research, 45, pp.85-93.

Islam, M.T., El-Basyouny, K. and Ibrahim, S.E., 2014. The impact of lowered residential speed limits on vehicle speed behavior. Safety science, 62, pp.483-494.

Kim, A.M., Wang, X., El-Basyouny, K. and Fu, Q., 2016. Operating a mobile photo radar enforcement program: A framework for site selection, resource allocation, scheduling, and evaluation. Case Studies on Transport 
Policy, 4(3), pp.218-229.

Kloeden, C.N., McLean, J. and Glonek, G.F.V., 2002. Reanalysis of travelling speed and the risk of crash involvement in Adelaide South Australia. Australian Transport Safety Bureau.

Li, R., El-Basyouny, K. and Kim, A., 2015. Before-and-after empirical Bayes evaluation of automated mobile speed enforcement on urban arterial roads. Transportation research record, 2516(1), pp.44-52.

Li, R., El-Basyouny, K. and Kim, A., 2019. A city-wide safety analysis of mobile speed enforcement.

Li, Y., Kim, A. and El-Basyouny, K., 2017, August. Scheduling resources in a mobile photo enforcement program. In 2017 4th International Conference on Transportation Information and Safety (ICTIS) (pp. 645-652). IEEE.

Li, Y., Xie, J., Kim, A.M. and El-Basyouny, K., 2019. Investigating trade-offs between optimal mobile photo enforcement programme plans. Journal of Multi-Criteria Decision Analysis, 26(1-2), pp.51-61.

Nilsson, G., 2004. Traffic safety dimensions and the power model to describe the effect of speed on safety (Doctoral dissertation, Univ.).

Organisation for Economic Cooperation and Development (OECD), Speed Management: Transportation Research Center. 2006. European Conference of Ministers of Transport. France.

Peden, M., 2008. World report on child injury prevention appeals to "Keep Kids Safe". Injury prevention, 14(6), pp.413-414.

Retting, R., 2017. Pedestrian traffic fatalities by state. Governors Highway Safety Association: Washington, DC, USA.

Richards, S.H., Wunderlich, R.C. and Dudek, C.L., 1985. Field evaluation of work zone speed control techniques. Transportation Research Record, 1035, pp.66-78.

Rothengatter, T., and C. Goldenbeld.1999. Police enforcement strategies to reduce traffic casualties in Europe. European Transport Safety Council.

Shalkamy, A., El-Basyouny, K. and Gargoum, S., 2018. Using LiDAR Data to Enrich the Diagnosis of Safety Problems and Collision Causes. In Australasian Road Safety Conference, Sydney, Australia.

Shalkamy, A., El-Basyouny, K. and Xu, H.Y., 2020. Voxel-Based Methodology for Automated 3D Sight Distance Assessment on Highways using Mobile Light Detection and Ranging Data. Transportation Research Record, 2674(5), pp.587-599.

Sisiopiku, V.P. and Patel, H., 1999. Study of the impact of police enforcement on motorists' speeds. Transportation Research Record, 1693(1), pp.31-36.

Snedecor, G.W. and Cochran, W.G., 1967. Statistical methods 6th edition. The Iowa State University.

Tay, R., 2005. Drink driving enforcement and publicity campaigns: are the policy recommendations sensitive to model specification?. Accident Analysis \& Prevention, 37(2), pp.259-266.

Tay, R., 2009. The effectiveness of automated and manned traffic enforcement. International journal of sustainable transportation, 3(3), pp.178-186.

Tay, R., 2010. Speed cameras improving safety or raising revenue?. Journal of Transport Economics and Policy (JTEP), 44(2), pp.247-257.

US Department of Commerce. SEMATECH e-handbook of statistical methods. 2006. http://www.itl.nist.gov/div898/handbook/. Accessed March 2020.

Vaa, T., 1997. Increased police enforcement: effects on speed. Accident Analysis \& Prevention, 29(3), pp.373-385.

Walter, L. and Broughton, J., 2011. Effectiveness of speed indicator devices: An observational study in South London. Accident Analysis \& Prevention, 43(4), pp.1355-1358.

Watson, B., Fresta, J., Whan, H., McDonald, J., Dray, R., Beuermann, C. and Churchward, R., 1996. Enhancing driver management in Queensland (No. HS-042 456).

Wilmots, B., Hermans, E., Brijs, T. and Wets, G., 2016. Speed control with and without advanced warning sign on the field: An analysis of the effect on driving speed. Safety science, 85, pp.23-32.

World Health Organization, 2015. Global status report on road safety 2015. World Health Organization.

Wrapson, W., Harré, N. and Murrell, P., 2006. Reductions in driver speed using posted feedback of speeding information: Social comparison or implied surveillance? Accident Analysis \& Prevention, 38(6), pp.11191126. 